OPEN

SUBJECT AREAS: BIOGEOCHEMISTRY

IMPACTS

MARINE CHEMISTRY

PHYSICAL OCEANOGRAPHY

Received

21 October 2012

Accepted

6 December 2012

Published

11 January 2013

Correspondence and requests for materials should be addressed to

C.G.F. (cgfichot@ gmail.com)

\section{Pan-Arctic distributions of continental runoff in the Arctic Ocean}

\author{
Cédric G. Fichot ${ }^{1}$, Karl Kaiser ${ }^{1,4}$, Stanford B. Hooker ${ }^{3}$, Rainer M. W. Amon ${ }^{4}$, Marcel Babin ${ }^{5,6}$, \\ Simon Bélanger7, Sally A. Walker ${ }^{4,8} \&$ Ronald Benner ${ }^{1,2}$
}

\begin{abstract}
${ }^{1}$ Marine Science Program, University of South Carolina, Columbia, South Carolina, 29208, USA, ${ }^{2}$ Department of Biological Sciences, University of South Carolina, Columbia, South Carolina, 29208, USA, ${ }^{3}$ Ocean Ecology Laboratory, NASA Goddard Space Flight Center, Greenbelt, Maryland, 20771, USA, ${ }^{4}$ Departments of Marine Sciences and Oceanography, Texas A\&M University, Galveston, Texas, 77553, USA, ${ }^{5}$ Takuvik Joint International Laboratory, UMI 3376, Université Laval (Canada) - CNRS (France), Département de Biologie and Québec-Océan, Université Laval, GIV OA6, Canada, 'Laboratoire d'Océanographie de Villefranche, UMR 7093, Université Pierre et Marie Curie (Paris 6)/Centre National de la Recherche Scientifique (CNRS),

Villefranche-sur-Mer Cedex, 06230, France, ${ }^{7}$ Department of Biology, Chemistry and Geography, BOREAS, Université du Québec à Rimouski, Rimouski, Québec, G5L 3A1, Canada, ${ }^{8}$ Department of Oceanography, Dalhousie University, Halifax, Nova Scotia, B3H 4R2, Canada.
\end{abstract}

Continental runoff is a major source of freshwater, nutrients and terrigenous material to the Arctic Ocean. As such, it influences water column stratification, light attenuation, surface heating, gas exchange, biological productivity and carbon sequestration. Increasing river discharge and thawing permafrost suggest that the impacts of continental runoff on these processes are changing. Here, a new optical proxy was developed and implemented with remote sensing to determine the first pan-Arctic distribution of terrigenous dissolved organic matter (tDOM) and continental runoff in the surface Arctic Ocean. Retrospective analyses revealed connections between the routing of North American runoff and the recent freshening of the Canada Basin, and indicated a correspondence between climate-driven changes in river discharge and tDOM inventories in the Kara Sea. By facilitating the real-time, synoptic monitoring of tDOM and freshwater runoff in surface polar waters, this novel approach will help understand the manifestations of climate change in this remote region.

ontinental runoff influences surface ocean processes throughout the Arctic. Rivers discharge about $3,300 \mathrm{~km}^{3} \mathrm{yr}^{-1}$ of buoyant freshwater to the Arctic Ocean ${ }^{1}$ where it sustains a halocline that isolates the upper 200-m layer from a warmer, saltier Atlantic layer2 ${ }^{2}$. This upper layer represents only $0.1 \%$ of the global ocean volume but receives $11 \%$ of global riverine discharge from a circumpolar drainage basin that encompasses over $10 \%$ of the world's land surface area. Riverine input is evident throughout the Arctic from low salinities and high concentrations of terrigenous dissolved organic matter (tDOM) in polar surface waters ${ }^{3,4}$. Arctic rivers discharge onto the world's largest continental shelves that surround and cover more than half of the Arctic Ocean area ${ }^{5}$. These river-influenced ocean margins are dominant features of the Arctic and important regions of sea-ice production, biological productivity, carbon sequestration and processes that drive biogeochemical cycles on a basin-wide scale.

The impact of rivers on the freshwater content and biogeochemistry of the Arctic Ocean is strongly influenced by the residence time of riverine inputs and their pathways to the North Atlantic Ocean. The average residence time of Arctic shelf water ranges from months to years depending on shelf region ${ }^{6,7}$. Variations in atmospheric forcing can affect residence time by dramatically altering continental runoff routing and distribution in the Arctic $\mathrm{Ocean}^{7,8}$. Climate-driven changes in runoff distribution have been linked to large inter-annual and decadal variations in the freshwater content of the Arctic Ocean, and these fluctuations have important ramifications for North Atlantic meridional overturning circulation'. Furthermore, changes in runoff routing through the Arctic Ocean can regulate the extent to which Arctic tDOM is incorporated into North Atlantic Deep Water (NADW) and distributed in the global ocean ${ }^{4}$. Despite their global significance, continental runoff routing and distribution in the Arctic remain poorly understood and difficult to predict in this remote and under-sampled region of the global ocean. Here, a new optical proxy for $\mathrm{tDOM}$ implemented using remote sensing of ocean color facilitates the synoptic and retrospective monitoring of continental runoff in the Arctic Ocean, and provides a novel approach to assess climate-driven changes in the Arctic. 


\section{Results}

Dissolved lignin is well established as a biomarker of tDOM in oceanic waters $^{10,11}$ and has been successfully applied as a tracer of riverine inputs in the Arctic Ocean ${ }^{3,4}$. However, its use relies on the collection of seawater samples and land-based laboratory analyses that prevent synoptic applications. Lignin is also an important chromophore in $\mathrm{tDOM}$, a property that facilitates detection using optical properties. Here, we demonstrate that the spectral slope coefficient of chromophoric dissolved organic matter (CDOM) between 275 and $295 \mathrm{~nm}\left(S_{275-295}\right)$ is a practical and reliable optical proxy for dissolved lignin and tDOM across various river-influenced ocean margins of the Arctic Ocean ${ }^{12,13}$ (Fig. 1a). An increase in $S_{275-295}$ is indicative of a decrease in the tDOM content of surface waters. Under the assumption that $S_{275-295}$ behaves conservatively, an increase in $S_{275-295}$ corresponds to a diminishing influence of continental runoff. Biological degradation has little effect on $S_{275-295}{ }^{13,14}$ and photodegradation of $\mathrm{tDOM}$ in polar surface waters is not extensive $^{4,15}$, thereby warranting the assumption and the use of $S_{275-295}$ as a tracer of tDOM and freshwater runoff in river-influenced ocean margins of the Arctic.

The practicality of the $S_{275-295}$ proxy resides in its amenability to remote sensing. The development of an empirical algorithm reveals that $S_{275-295}$ can be estimated from ocean color with excellent and consistent accuracy (within $\pm 4 \%$ ) over the broad range of water types and $S_{275-295}$ values observed in the Arctic Ocean (Fig. 1b). The strong connection between $S_{275-295}$ and ocean color in river-influenced ocean margins exists because the optical property $S_{275-295}$ is an excellent tracer of $\mathrm{tDOM}^{13}$ and the gradients of ocean color in riverinfluenced ocean margins are primarily driven by the constituents of continental runoff. The $S_{275-295}$ algorithm thus facilitates the synoptic and real-time monitoring of tDOM and freshwater runoff in the Arctic using ocean-color remote sensing.

Implementation of the $S_{275-295}$ algorithm using MODIS Aqua ocean color provides the first pan-Arctic view of average tDOM distributions in river-influenced ocean margins during August 2002-2009 (Fig. 1c). The influence of the three largest Arctic rivers on tDOM distributions is evident along the entire Siberian margin. One of the most striking features is the overwhelming amount of tDOM in the Laptev and East Siberian Seas, indicating a large portion of Eurasian river tDOM and runoff is routed alongshore in an eastward direction. This observation is supported by measurements of high in situ concentrations of dissolved organic carbon of terrigenous origin in the East Siberian Sea in August $2008^{16}$, and is consistent with shelf water residence times of several years in this region ${ }^{6,7}$. Low $S_{275-295}$ values along the Alaskan coast in the Chukchi Sea depict the transport of Yukon River tDOM to the Arctic Ocean in the Alaska Coastal Current and indicate notable tDOM contributions by smaller Alaskan rivers (e.g., Noatak and Kobuk Rivers). Most of the runoff and tDOM from the Mackenzie River enters the Beaufort Sea and appears to be entrained in the gyre circulation of the southern Canada Basin. A relatively small fraction of the discharge from the Mackenzie River was routed to the Labrador Sea via the Canadian Arctic Archipelago (CAA).

Assessment of inter-annual variability in tDOM distribution revealed a change in the routing of Mackenzie River discharge over the last decade (Fig. 2; Supplementary Figs. S3 and S4). The Mackenzie River outflow progressed from an alongshore, eastward path to the CAA in 2002 (Fig. 2a) to a cross-shelf, northwestward path to the Canada Basin since 2006 (Fig. 2b). This routing switch has important implications for the fate of North American runoff and tDOM. Routing through the CAA favors the export of North American tDOM to the Labrador Sea ${ }^{17}$. Although the magnitude of this export remains unknown, deep ocean convection in the Labrador Sea can sequester tDOM in North Atlantic Deep Water for centuries ${ }^{4}$. In contrast, routing to the Canada Basin contributes to longer-term storage of runoff and processing of tDOM within the Beaufort Gyre and Arctic Ocean ${ }^{4,15}$. This decadal shift to greater export of Mackenzie River runoff to the Canada Basin during
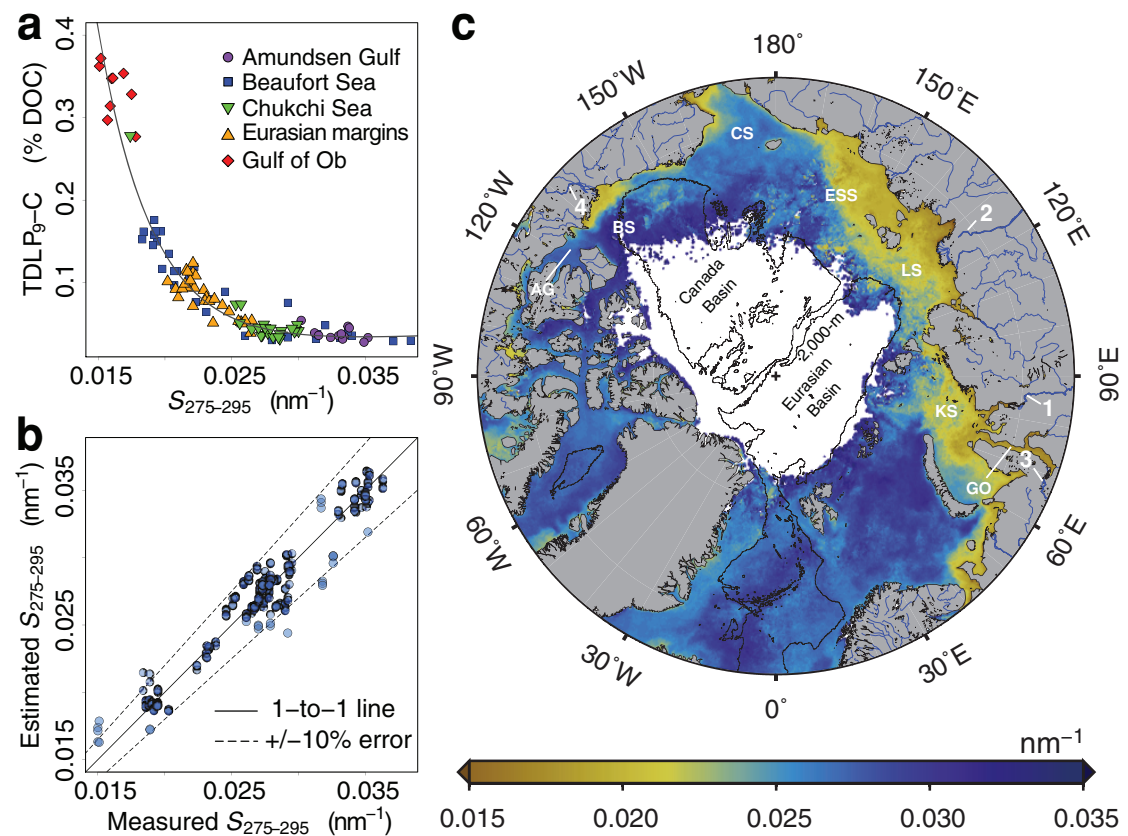

Figure $1 \mid$ The CDOM spectral slope coefficient, $S_{275-295}$, as a tracer of riverine inputs in the Arctic Ocean. (a) The relationship between $S_{275-295}$ and dissolved lignin carbon yield (TDLP 9 -C) across various Arctic river-influenced ocean margins. (b) A performance evaluation of the $S_{275-295}$ algorithm. On average, $S_{275-295}$ can be estimated from ocean color within $4 \%$ of $S_{275-295}$ values measured in situ. (c) Implementation of the algorithm using MODIS Aqua ocean color providing a pan-Arctic view of an August climatology (2002-2009) of $S_{275-295}$. Increasing $S_{275-295}$ values are indicative of a decreasing fraction of tDOM. The four largest Arctic rivers are labeled and ranked in order of decreasing discharge: Yenisei (1), Lena (2), $\mathrm{Ob}$ (3), and Mackenzie (4). River-influenced margins of the Arctic are labeled: Gulf of Ob (GO), Kara Sea (KS), Laptev Sea (LS), East Siberian Sea (ESS), Chukchi Sea (CS), Beaufort Sea (BS) and Amundsen Gulf (AG). The contour lines represent the 2000-m isobath. 
a

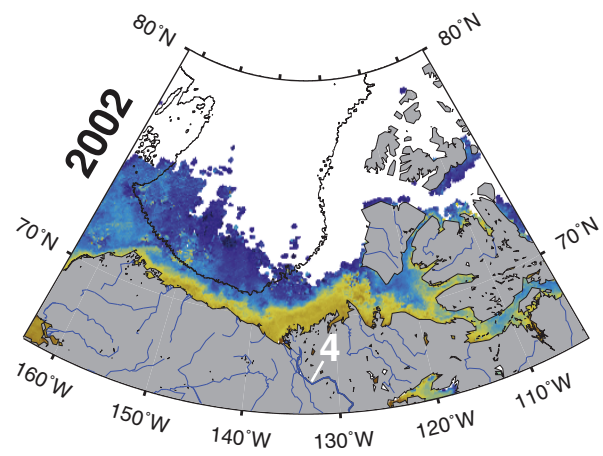

b

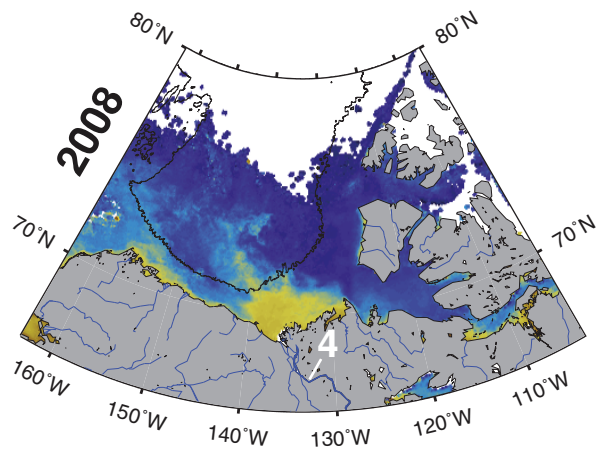

$\mathrm{nm}^{-1}$

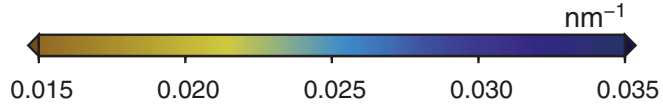

Figure $2 \mid$ Inter-annual changes in the routing of Mackenzie River runoff. (a) The Mackenzie River outflow in 2002, showing eastward transport of North American runoff to the Canadian Arctic Archipelago. (b) The Mackenzie River outflow in 2008, showing northwestward transport of North American runoff to the Canada Basin. A progressive switch from eastward to northwestward routing occurred between 2002 and 2011 (Supplementary Figs. S3 and S4) and coincides with the rapid freshening of the Canada Basin. The $S_{275-295}$ algorithm was implemented using 4-km resolution, yearlybinned, MODIS Aqua ocean color. The Mackenzie River is labeled (4). The contour line represents the 2000-m isobath and outlines the Canada Basin.

2006-2011 could contribute to less North American tDOM being sequestered in the deep ocean.

The routing of Mackenzie River outflow since 2006 coincides with observations of a rapid accumulation of freshwater in the Canada Basin. Freshening began in the 1990s and accelerated in the late $2000 \mathrm{~s}^{18-21}$. The realization that a large accumulation of freshwater in the Canada Basin could impact global ocean circulation stimulated research to identify the freshwater sources and climatic forcing responsible for observed changes in salinity. Pacific water, ice-melt, precipitation and river runoff are distinct sources of freshwater to the Canada Basin. The relative contributions of these freshwater sources to the freshening are typically estimated using tracers (e.g. $\delta^{18} \mathrm{O}$, alkalinity, salinity) or are indirectly calculated using complex models $s^{9,20,22-25}$. The lignin-based $S_{275-295}$ proxy presented here substantiates the riverine origin of freshwater and provides a direct means to distinguish continental runoff from other freshwater sources using remote sensing.

The acceleration of the Beaufort Gyre due to the strengthening of the Beaufort $\mathrm{High}^{26}$ and routing of Eurasian river runoff to the Canada Basin driven by the Arctic Oscillation ${ }^{9}$ are complementary and currently leading explanations for the freshening of the Basin ${ }^{27}$. The remotely sensed runoff distributions presented in this study (Fig. 2 and Supplementary Figs. S3 and S4) further suggest the recurrent influx of Mackenzie River runoff to the Canada Basin in the late 2000s was also a significant source of freshwater to the Basin and contributed to the freshening. The temporal sequence of the
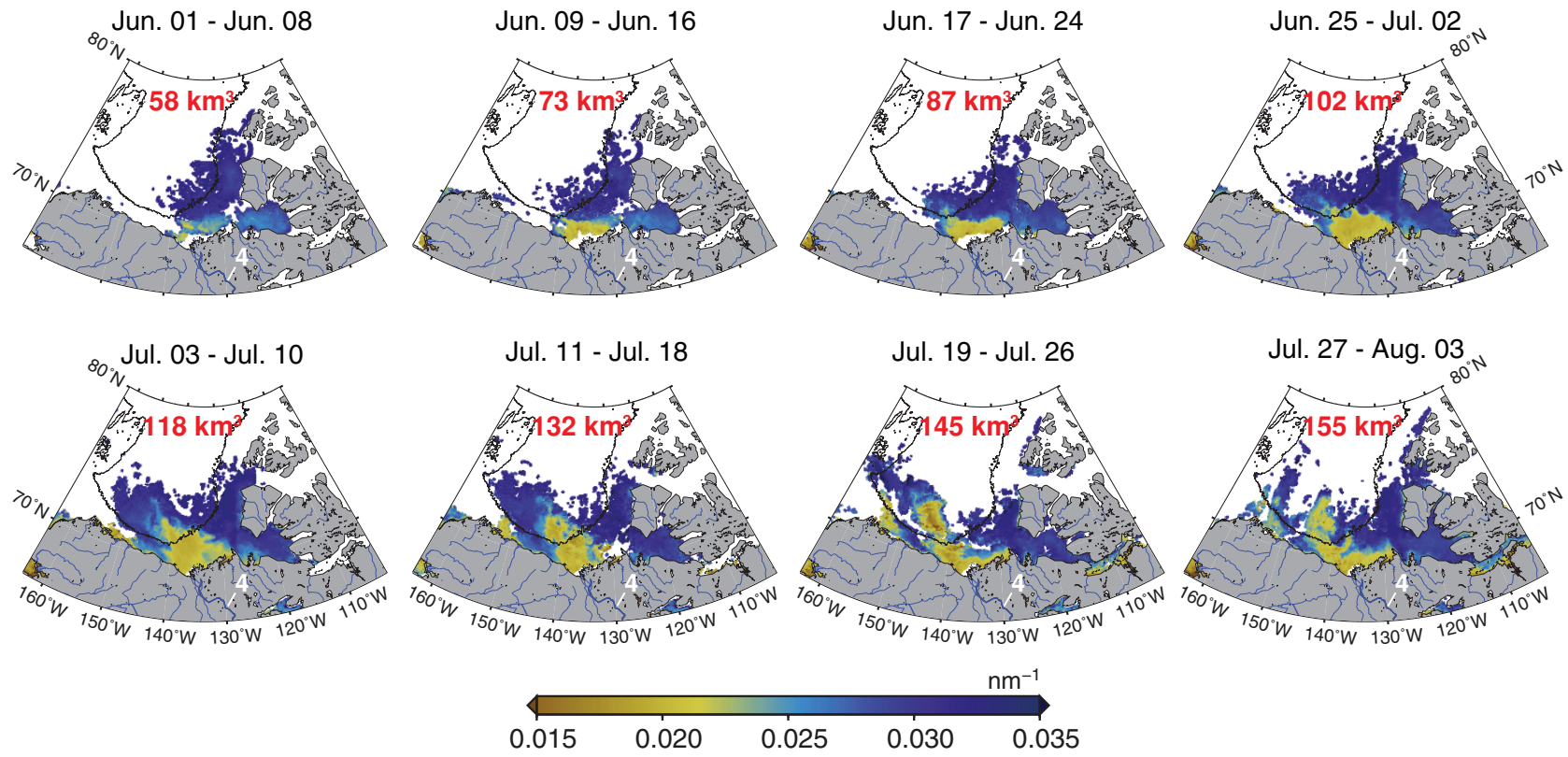

Figure 3 Temporal sequence of the Mackenzie River freshet release into the Canada Basin during June and July 2008. The $S_{275-295}$ algorithm was implemented using 4-km resolution, 8-day-binned, MODIS Aqua ocean color acquired between June 1 and August 3. The discharge value $\left(\mathrm{km}^{3}\right)$ displayed on each panel indicates the cumulative Mackenzie River discharge released between May 1 (start of the freshet) and the end of each 8-day period. The contour line represents the 2000-m isobath and delineates the Canada Basin. The Mackenzie River is labeled (4). 

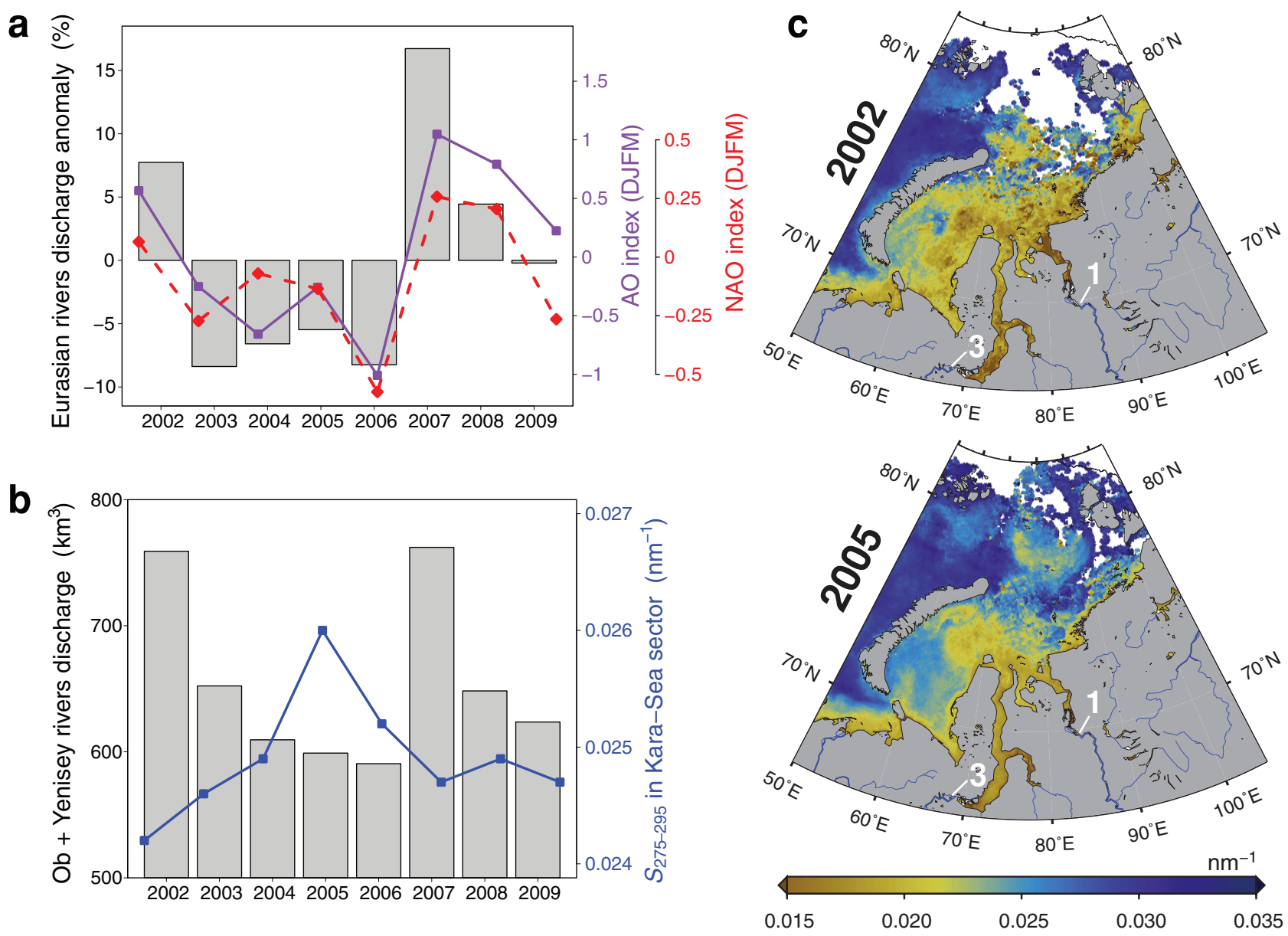

Figure 4 Climatic forcing of major Eurasian riverine inputs. (a) The North Atlantic Oscillation (NAO) and Arctic Oscillation (AO) wintertime indices (DJFM: Dec-Jan-Feb-Mar) in relation to the combined discharge anomaly of the Yenisei, Lena and Ob rivers between 2002 and 2009 . High NAO and AO indices are typically associated with higher precipitation over Northern Eurasia. River discharge is calculated as the cumulative discharge from May 1 to August 30, and the anomaly is relative to the 2002-2009 average. (b) Average $S_{275-295}$ values for surface waters of the Kara Sea in relation to the combined discharge of the Yenisei and $\mathrm{Ob}$ rivers between 2002 and 2009. The $S_{275-295}$ values for the Kara Sea were calculated as the average value in the region displayed in panel (c). River discharge is calculated as the cumulative discharge from May 1 to August 30. (c) Distributions of riverine inputs during high (2002) and low (2005) discharge years. The years correspond to low and high average $S_{275-295}$ values observed in the Kara Sea between 2002 and 2009 . The $S_{275-295}$ algorithm was implemented using MODIS Aqua ocean color data averaged from May to October. The Yenisei and Ob rivers are labeled (1) and (3), respectively.

Mackenzie River discharge in 2008 provides unambiguous evidence that the spring freshet was directly and rapidly injected into the Canada Basin during June and July (Fig. 3). In situ measurements of salinity, $\delta^{18} \mathrm{O}$, and alkalinity from an independent study ${ }^{20}$ corroborate that Mackenzie River runoff was a minor source of freshwater to the Canada Basin in the early 2000s but increased in the southern part of the Basin in 2007.

The contribution of North American runoff to the Canada Basin freshwater budget appears to be shifting in response to climatic forcing. A freshwater budget based on data from 2003-2004 estimated about $40 \%$ of North American runoff enters the Canada Basin ${ }^{22}$. The mean freshwater residence time in the Basin is about 10 years $^{22}$, so this estimate is representative of the decade leading up to 2004 . Although significant freshwater contributions from the Mackenzie River to the Basin were observed during that decade ${ }^{28}$, this estimate does not integrate the increasing contributions from North American runoff since 2006. The detailed progression of the 2008 Mackenzie River outflow indicated up to $155 \mathrm{~km}^{3}$ of Mackenzie freshwater was released into the Canada Basin in June and July alone (Fig. 3), indicating more than half of the discharge from the Mackenzie has been entering the Canada Basin since 2006. Increasing contributions of North American runoff to the Canada Basin are consistent with enhanced Ekman pumping resulting from the wind-driven spin-up of the Beaufort Gyre ${ }^{26}$ and therefore appear to result from recent trends in climate variability.

Discharge from major Arctic rivers has increased over the past decades in response to climate variability ${ }^{29-31}$. Climatic forcing of river discharge is evident between 2002 and 2009 from the strong correspondence between the North Atlantic Oscillation (NAO) or Arctic Oscillation ( $\mathrm{AO}$ ) wintertime indices and the river discharge anomaly of Eurasian rivers (Fig. 4a). Manifestations of interannual discharge fluctuations in the Arctic Ocean are best illustrated in the Kara Sea, which receives inputs from the $\mathrm{Ob}$ and Yenisei rivers. The Kara Sea is a semi-enclosed margin that is largely ice-free during summer, which facilitates inter-annual comparisons of remotely sensed variables. Inter-annual comparisons revealed consistency between discharge from the $\mathrm{Ob}$ and Yenisei rivers and the average $S_{275-295}$ value for the Kara-Sea sector (Fig. 4b). The correspondence between discharge and tDOM in the Kara Sea is particularly striking when comparing 2002 and 2005, which are representative of high and low discharge years between 2002 and 2009 (Fig. 4c). This demonstrates climatedriven changes in the tDOM inventory of the surface Arctic Ocean are traceable using this approach. 


\section{Discussion}

The $S_{275-295}$ proxy and algorithm presented in this study facilitate the real-time and synoptic monitoring of tDOM and freshwater runoff in surface polar waters. The foundation of the $S_{275-295}$ proxy on the lignin biomarker is fundamental to the approach. The "terrigenous" attribute of lignin substantiates the riverine origin of dissolved organic matter and freshwater. Its "chromophoric" property, on the other hand, facilitates implementation with remote sensing. Although the Arctic remains one of the most challenging environments for remote sensing, it is also a region where remote sensing has much to offer given the logistical restrictions and high costs of field surveys, particularly on the Siberian shelves. The applicability of the approach will improve as the extent and duration of sea-ice cover decrease, allowing for greater spatial and temporal coverage.

New capabilities to monitor surface tDOM distributions will prove valuable for understanding future climate-driven changes in the biogeochemistry of the Arctic. Permafrost thawing and precipitation in drainage basins of Arctic rivers are projected to intensify with escalating atmospheric temperatures and thereby enhance the mobilization of soil organic matter to the Arctic Ocean ${ }^{32-36}$. The fate of this material and its effects on biogeochemical cycles will depend on its routing and residence time in polar surface waters ${ }^{4}$. Furthermore, processing of organic matter in surface waters is influenced by factors that are currently being altered by climate change (e.g., ice cover, water temperature). Multiyear records of remotely sensed tDOM distributions provide direct evidence of how the routing, inventory, storage and residence time of $\mathrm{tDOM}$ in surface polar waters change in response to climatic forcing. Such applications will thus provide crucial information for understanding the fate of immobilized soil organic matter and its impacts on biogeochemical cycles in this rapidly changing Arctic environment.

Finally, remote sensing of continental runoff provides useful insights about the sources of freshwater in the Arctic Ocean. Ice melt, precipitation and runoff are all increasing under the current climatic trends ${ }^{31,37}$, and are altering the freshwater budget of the Arctic Ocean. Remotely sensed runoff distributions provide direct evidence of continental runoff contributions to specific regions of the surface Arctic Ocean, and will thereby help understand the mechanisms responsible for future changes in the Arctic freshwater budget. It is important to remember, however, that the uncoupling of river water from its tDOM component during the winter freeze-thaw cycle ${ }^{38}$ hampers the use of this approach to assess year-to-year changes in freshwater runoff storage. Future applications will also likely include studying the influence of continental runoff on biological processes, such as primary production, in polar surface waters.

\section{Methods}

Surface water samples and data $(n=106)$ used to establish the relationship between $S_{275-295}$ and TDLP ${ }_{9}$-C (Fig. 1a) were acquired during several field expeditions to the Arctic Ocean between 2005 and 2010, including the Amundsen Gulf, Gulf of Ob, and the Beaufort, Chukchi, Laptev and East Siberian Seas (Supplementary Fig. S1). Samples for DOC and CDOM were filtered onboard and analyzed in the home laboratory using high temperature combustion ${ }^{39}$ and a dualbeam UV-visible spectrophotometer ${ }^{12,13}$, respectively. Samples for dissolved lignin (1-10 L) were extracted onboard ${ }^{40}$ and analyzed using the cupric oxide oxidation method and gas chromatography with mass spectrometry ${ }^{41}$. DOC-normalized yields of nine lignin phenols $\left(\mathrm{TDLP}_{9}-\mathrm{C}\right)$ were calculated ${ }^{13}$, and the non-linear regression of $\mathrm{TDLP}_{9}-\mathrm{C}$ on $S_{275-295}$ utilized the exponential function shown in equation (1),

$$
\mathrm{TDLP}_{9}-\mathrm{C}=\exp \left(a+\beta S_{275-295}\right)+\exp \left(\gamma S_{275-295}\right)+\delta \exp \left(S_{275-295}\right)
$$

where $\alpha=2.7428, \beta=-245.5899, \gamma=1.6669$, and $\delta=-0.9932$ are the derived regression coefficients.

The in situ measurements of ocean color $(n=236)$ and concurrent CDOM samples used in the $S_{275-295}$ algorithm development (Fig. 1b) were collected during the Malina and ICESCAPE field expeditions (Supplementary Fig. S2). Multispectral remote-sensing reflectances, $R_{r s}(\lambda)$, were derived for 5 wavelengths $(\lambda=443,488$, 531,555 and $667 \mathrm{~nm}$ ) from profiles made with a Biospherical Compact-Optical Profiling System (C-OPS) ${ }^{42}$, and the corresponding CDOM samples were collected and analyzed according to NASA standard protocols ${ }^{43}$. "Measured" $S_{275-295}$ were calculated from CDOM absorption coefficient spectra, and regressed on $R_{r s}(\lambda)$ using the multiple linear regression described in equation (2),

$$
\begin{aligned}
\ln \left[S_{275-295}\right]= & a+\beta \ln [\operatorname{Rrs}(443)]+\gamma \ln [\operatorname{Rrs}(488)]+ \\
& \delta \ln [\operatorname{Rrs}(531)]+\varepsilon \ln [\operatorname{Rrs}(555)]+\zeta \ln [\operatorname{Rrs}(667)]
\end{aligned}
$$

where $\alpha=-3.4567, \beta=0.4299, \gamma=0.0924, \delta=-1.2649, \varepsilon=0.8885$, and $\zeta=-0.1025$ are the derived regression coefficients. This data set covers a broad range of water types found in river-influenced ocean margins, including high-CDOM and sediment-laden coastal environments, productive waters at intermediate salinities and oligotrophic waters at higher salinities. The inclusion of data from the Chukchi Sea in summer (ICESCAPE) further demonstrates that the algorithm performs very well in areas where tDOM is relatively low and biogenic particles are abundant and variable. Similar accuracy of $S_{275-295}$ retrievals was obtained using data collected seasonally in the northern Gulf of Mexico in various water types ranging from riverine to oligotrophic, thereby indicating that the approach used in the algorithm is robust.

MODIS Aqua data were accessed from the NASA ocean color website (http:// oceancolor.gsfc.nasa.gov/). Monthly NAO and AO indices were acquired from the NOAA Earth System Research Laboratory website (http://www.esrl.noaa.gov/psd/ data/climateindices). The Mackenzie River discharge data were obtained from the Environment Canada Water Office website (http://www.wateroffice.ec.gc.ca). Eurasian river discharge was obtained from the ArcticRIMS website (http:// rims.unh.edu/data.shtml)

1. Rachold, V. et al. in The Organic Carbon Cycle in the Arctic Ocean (eds Stein, R. \& MacDonald, R. W. ) Ch. 2 Modern Terrigenous Organic Carbon Input to the Arctic Ocean. 33-55 (Springer, 2004).

2. Aagaard, K. \& Carmack, E. C. The Role of Sea Ice and Other Fresh Water in the Arctic Circulation. J. Geophys. Res. 94, 14485-14498 (1989).

3. Opsahl, S., Benner, R. \& Amon, R. M. W. Major flux of terrigenous dissolved organic matter through the Arctic Ocean. Limnol. Oceanogr. 44, 2017-2023 (1999).

4. Benner, R., Louchouarn, P. \& Amon, R. M. W. Terrigenous dissolved organic matter in the Arctic Ocean and its transport to surface and deep waters of the North Atlantic. Global Biogeochem. Cycles 19, GB2025 (2005).

5. Jakobsson, M., Grantz, A., Kristoffersen, Y. \& Macnab, R. in The Organic Carbon Cycle in the Arctic Ocean (eds Stein, R. \& MacDonald, R. W. ) Ch. 1.1 Bathymetry and Physiography of the Arctic Ocean and its Constituent Seas. 1-6 (Springer, 2004).

6. Schlosser, P., Bauch, D., Fairbanks, R. \& Bönisch, G. Arctic river-runoff: mean residence time on the shelves and in the halocline. Deep-Sea Res. Part I 41, 1053-1068 (1994).

7. MacDonald, R. W., Sakshaug, E. \& Stein, R. in The Organic Carbon Cycle in the Arctic Ocean (eds Stein, R. \& MacDonald, R. W. ) Ch. 1.2 The Arctic Ocean: Modern Status and Recent Climate Change. 6-12 (Springer, 2004).

8. Bauch, D. et al. Exchange of Laptev Sea and Arctic Ocean halocline waters in response to atmospheric forcing. J. Geophys. Res. 114, C05008 (2009).

9. Morison, J. et al. Changing Arctic Ocean freshwater pathways. Nature 481, 66-70 (2012).

10. Meyers-Schulte, K. J. \& Hedges, J. I. Molecular evidence for a terrestrial component of organic matter dissolved in ocean water. Nature 321, 61-63 (1986).

11. Opsahl, S. \& Benner, R. Distribution and cycling of terrigenous dissolved organic matter in the ocean. Nature 386, 480-482 (1997).

12. Fichot, C. G. \& Benner, R. A novel method to estimate DOC concentrations from CDOM absorption coefficients in coastal waters. Geophys. Res. Lett. 38, L03610 (2011).

13. Fichot, C. G. \& Benner, R. The spectral slope coefficient of chromophoric dissolved organic matter $\left(S_{275-295}\right)$ as a tracer of terrigenous dissolved organic carbon in river-influenced ocean margins. Limnol. Oceanogr 57, 1453-1466 (2012).

14. Helms, J. R. et al. Absorption spectral slopes and slope ratios as indicators of molecular weight, source, and photobleaching of chromophoric dissolved organic matter. Limnol. Oceanogr 53, 955-969 (2008).

15. Bélanger, S. et al. Photomineralization of terrigenous dissolved organic matter in Arctic coastal waters from 1979 to 2003: Interannual variability and implications of climate change. Global Biogeochem. Cycles 20, GB4005 (2006).

16. Alling, V. et al. Nonconservative behavior of dissolved organic carbon across the Laptev and East Siberian seas. Global Biogeochem. Cycles 24, GB4033 (2010).

17. Walker, S. A., Amon, R. M. W., Stedmon, C., Duan, S. \& Louchouarn, P. The use of PARAFAC modeling to trace terrestrial dissolved organic matter and fingerprint water masses in coastal Canadian Arctic surface waters. J. Geophys. Res. 114, G00F06 (2009).

18. Proshutinsky, A. et al. Beaufort Gyre freshwater reservoir: State and variability from observations. J. Geophys. Res. 114, C00A10 (2009).

19. McPhee, M. G., Proshutinsky, A., Morison, J. H., Steele, M. \& Alkire, M. B. Rapid change in freshwater content of the Arctic Ocean. Geophys. Res. Lett. 36, L10602 (2009).

20. Yamamoto-Kawai, M. et al. Surface freshening of the Canada Basin, 2003-2007: River runoff versus sea ice meltwater. J. Geophys. Res. 114, C00A05 (2009). 
21. Rabe, B. et al. An assessment of Arctic Ocean freshwater content changes from the 1990s to the 2006-2008 period. Deep-Sea Res. Part I 58, 173-185 (2011).

22. Yamamoto-Kawai, M., McLaughlin, F. A., Carmack, E. C., Nishino, S. \& Shimada, K. Freshwater budget of the Canada Basin, Arctic Ocean, from salinity, $\delta^{18} \mathrm{O}$, and nutrients. J. Geophys. Res. 113, C01007 (2008).

23. Macdonald, R. W., McLaughlin, F. A. \& Carmack, E. C. Fresh water and its sources during the SHEBA drift in the Canada Basin of the Arctic Ocean. Deep Sea Research Part I: Oceanographic Research Papers 49, 1769-1785 (2002).

24. Serreze, M. C. et al. The large-scale freshwater cycle of the Arctic. J. Geophys. Res. 111, C11010 (2006).

25. Schlosser, P. et al. Decrease of river runoff in the upper waters of the Eurasian Basin, Arctic Ocean, between 1991 and 1996: Evidence from $\delta^{18} \mathrm{O}$ data. Geophys. Res. Lett. 29, 1289 (2002).

26. Giles, K. A., Laxon, S. W., Ridout, A. L., Wingham, D. J. \& Bacon, S. Western Arctic Ocean freshwater storage increased by wind-driven spin-up of the Beaufort Gyre. Nature Geosciences 5, 194-197 (2012).

27. Mauritzen, C. Oceanography: Arctic freshwater. Nature Geosciences 5, 162-164 (2012).

28. Macdonald, R. W., Carmack, E. C., McLaughlin, F. A., Falkner, K. K. \& Swift, J. H. Connections among ice, runoff and atmospheric forcing in the Beaufort Gyre. Geophys. Res. Lett. 26, 2223-2226 (1999).

29. Peterson, B. J. et al. Increasing river discharge to the Arctic Ocean. Science 298, 2171-2173 (2002)

30. Shiklomanov, A. I. \& Lammers, R. B. Record Russian river discharge in 2007 and the limits of analysis. Environ. Res. Lett. 4, 045015 (2009).

31. McClelland, J. W., Déry, S. J., Peterson, B. J., Holmes, R. M. \& Wood, E. F. A pan-arctic evaluation of changes in river discharge during the latter half of the 20th century. Geophys. Res. Lett. 33, L06715 (2006).

32. Benner, R., Benitez-Nelson, B., Kaiser, K. \& Amon, R. M. W. Export of young terrigenous dissolved organic carbon from rivers to the Arctic Ocean. Geophys. Res. Lett. 31, L05305 (2004).

33. Frey, K. E. \& Smith, L. C. Recent temperature and precipitation increases in West Siberia and their association with the Arctic Oscillation. Polar Res. 22, 287-300 (2003).

34. Frey, K. E. \& Smith, L. C. Amplified carbon release from vast West Siberian peatlands by 2100. Geophys. Res. Lett. 32, L09401 (2005).

35. Guo, L., Ping, C.-L. \& Macdonald, R. W. Mobilization pathways of organic carbon from permafrost to arctic rivers in a changing climate. Geophys. Res. Lett. 34, L13603 (2007)

36. Amon, R. M. W. et al. Dissolved organic matter sources in large Arctic rivers. Geochim. Cosmochim. Acta 94, 217-237 (2012).

37. Serreze, M. C. et al. Observational Evidence of Recent Change in the Northern High-Latitude Environment. Climatic Change 46, 159-207 (2000).

38. Amon, R. M. W. in The Organic Carbon Cycle in the Arctic Ocean (eds Stein, R. \& MacDonald, R. W.) Ch. 4 The Role of Dissolved Organic Matter for the Organic Carbon Cycle in the Arctic Ocean. 83-99 (Springer, 2004).

39. Benner, R. \& Strom, M. A critical evaluation of the analytical blank associated with DOC measurements by high-temperature catalytic oxidation. Mar. Chem. 41, 153-160 (1993).

40. Louchouarn, P., Opsahl, S. \& Benner, R. Isolation and quantification of dissolved lignin from natural waters using solid-phase extraction and GC/MS. Anal. Chem. 72, 2780-2787 (2000).

41. Kaiser, K. \& Benner, R. Characterization of lignin by gas chromatography and mass spectrometry using a simplified $\mathrm{CuO}$ oxidation method. Anal. Chem. $\mathbf{8 4}$ 459-464 (2012).
42. Hooker, S., Morrow, J. \& Matsuoka, A. The $1 \%$ and $1 \mathrm{~cm}$ perspective in deriving and validating AOP data products. Biogeosciences Discuss 9, 9487-9531 (2012).

43. Pegau, S. et al. in Ocean Optics Protocols For Satellite Ocean Color Sensor Validation, Revision 4 (eds James L. Mueller, Giulietta S. Fargion \& Charles R. McClain). Vol. IV, Inherent Optical Properties: Instruments, Characterizations, Field Measurements and Data Analysis Protocols. (2002).

\section{Acknowledgements}

This study was conducted as part of: 1) the Malina Scientific Program (http:// malina.obs-vlfr.fr) funded by ANR (Agence nationale de la recherche), INSU-CNRS (Institut national des sciences de l'univers, Centre national de la recherche scientifique), CNES (Centre national d'études spatiales) and ESA (European Space Agency); 2) the Circumpolar Flaw Lead (CFL) study (http://www.ipy-api.gc.ca/pg_IPYAPI_029-eng.html) funded by the Government of Canada (IPY \#96); 3) the Impacts of Climate on the Eco-Systems and Chemistry of the Arctic Pacific Environment (ICESCAPE) program (http://www.espo.nasa.gov/icescape/) funded by NASA (National Aeronautics and Space Administration); 4) the Nansen and Amundsen Basin Observational System (NABOS) project (http://nabos.iarc.uaf.edu/index.php) funded by the US-NSF (National Science Foundation), NOAA (National Oceanographic and Atmospheric Administration), the ONR (Office of Naval Research) and JAMSTEC (Japan Marine Science and Technology Center). This work was directly supported by NSF grants 0713915 and 0850653 to R.B., NSF grants $0229302,0425582,0713991$ to R.A., and NASA funding to S.H.

We thank the following people: the crews of the USCGC Healy, CCGS Amundsen and Russian icebreaker Kapitan Dranitsyn for assistance with sample collection, Dr. Jolynn Carroll for collecting the Gulf-of-Ob samples, Vanessa Wright, Joaquin Chavez and Aimée Nealy for assisting S.H. with collection and analysis of Malina and ICESCAPE data, and Yuan Shen for DOC analysis of Malina samples.

\section{Author contributions}

Development of the main concept, design of the figures and writing of the text were done by C.F. and R.B. The ICESCAPE and CFL samples were collected and analyzed by C.F. (DOC, CDOM, lignin). The Malina samples were collected by R.B. and analyzed by C.F. (lignin) and S.W. (CDOM). The NABOS samples were collected and analyzed by K.K. (DOC, lignin) and S.W. (CDOM). The Gulf-of-Ob samples were processed by C.F. (DOC, CDOM, lignin). S.H. collected and processed the remote-sensing reflectances and CDOM measurements used to develop the algorithm. M.B. and S.B. facilitated research on the CFL, Malina and ICESCAPE expeditions. C.F., R.B., K.K. and R.A. discussed the results and all authors commented on the manuscript.

\section{Additional information}

Supplementary information accompanies this paper at http://www.nature.com/ scientificreports

Competing financial interests: The authors declare no competing financial interests. License: This work is licensed under a Creative Commons Attribution-NonCommercial-NoDerivs 3.0 Unported License. To view a copy of this license, visit http://creativecommons.org/licenses/by-nc-nd/3.0/

How to cite this article: Fichot, C.G. et al. Pan-Arctic distributions of continental runoff in the Arctic Ocean. Sci. Rep. 3, 1053; DOI:10.1038/srep01053 (2013). 